\title{
«Me acompañan, me informan, me ayudan». Prácticas de uso de las tecnologías de información y comunicación en jóvenes del Sur del estado de Yucatán, México*
}

\author{
Inés Cornejo Portugal \\ Universidad Nacional Autónoma de México, Ciudad de México, México \\ icportugal@ hotmail.com
}

\begin{abstract}
RESUMEN
En la República Mexicana, los municipios de Dzán, Oxkutzcab, Santa Elena y Ticul están ubicados en el sur del Estado de Yucatán. Se caracterizan por la producción de cítricos, el alto índice migratorio hacia Estados Unidos, el atraso educativo y elevados niveles de pobreza. En este contexto, los pobladores tienen acceso a diferentes dispositivos tecnológicos y plataformas que utilizan para indagar sobre temáticas específicas. Así, el objetivo de este trabajo es explorar qué hacen los jóvenes yucatecos con las tecnologías que tienen a su alcance. Conjeturamos, además, que las prácticas de uso de las tecnologías parecen estar determinadas tanto por el contexto institucional educativo, como por la necesidad de comunicación para establecer o conservar algún tipo de vinculación afectiva con los padres o familiares que emigraron y se asentaron de manera definitiva en Estados Unidos.
\end{abstract}

Palabras clave: Juventud, tecnologías de información y comunicación , prácticas de uso, migración, rezago educativo

\section{«They are with me, they keep me updated, they help me». Practices in use of information and communications technology, and communication by young people in the South of the state of Yucatan, in Mexico}

\begin{abstract}
In the Mexican Republic, municipalities of Dzán, Oxkutzcab, Santa Elena, and Ticul are located in the south of the State of Yucatan. They are characterized by the productions of citrus fruits, the high rate of migration to the United States, the educational backwardness, and high levels of poverty. In this context, the residents have access to different technological devices and platforms that they used to inquire about specific themes. Thus, the purpose of this work is to investigate what the young Yucateros do with the technology they have at their disposal. Besides, we conjecture that the practices of using technologies appear to be determined both by the institutional educational context and by the necessity of communication to establish or preserve some kind of emotional bond with parents or relatives that emigrated and established permanently in the United States.
\end{abstract}

KeYwords: Youth, information and communications technologies, use practices, migration, educational backwardness

* Agradezco al licenciado Óscar Nieto Villegas la atenta revisión bibliográfica y hemerográfica para realizar este trabajo. 
En la República Mexicana, Dzán, Oxkutzcab, Santa Elena y Ticul son municipios ubicados en el Sur del estado de Yucatán; la zona se caracteriza por la producción y comercialización de cítricos, el alto índice migratorio hacia Estados Unidos y los elevados niveles de pobreza. En este contexto, los pobladores tienen acceso a diferentes dispositivos tecnológicos (teléfonos inteligentes, tabletas, computadoras) y plataformas (páginas web, sitios electrónicos, redes sociales) que utilizan con fines determinados e intereses específicos para atender preguntas e indagar sobre temáticas diversas. Así, el objetivo de este trabajo es explorar qué hacen los jóvenes del Sur del estado con las tecnologías que tienen a su alcance.

El escrito se divide en tres apartados: el primero es una breve exposición del índice migratorio y el envío de remesas de Estados Unidos a los lugares de destino; el segundo, expositivo también, abarca las condiciones de pobreza y la situación educativa; por último, el tercer apartado está subdividido en secciones para conocer y explorar qué acontece con los jóvenes yucatecos y las tecnologías. Asimismo, se trata de indagar con los docentes que imparten las asignaturas de Informática, Computación y Competencias digitales cómo integran los usos tecnológicos del estudiantado para la impartición de sus materias en el ámbito escolar.

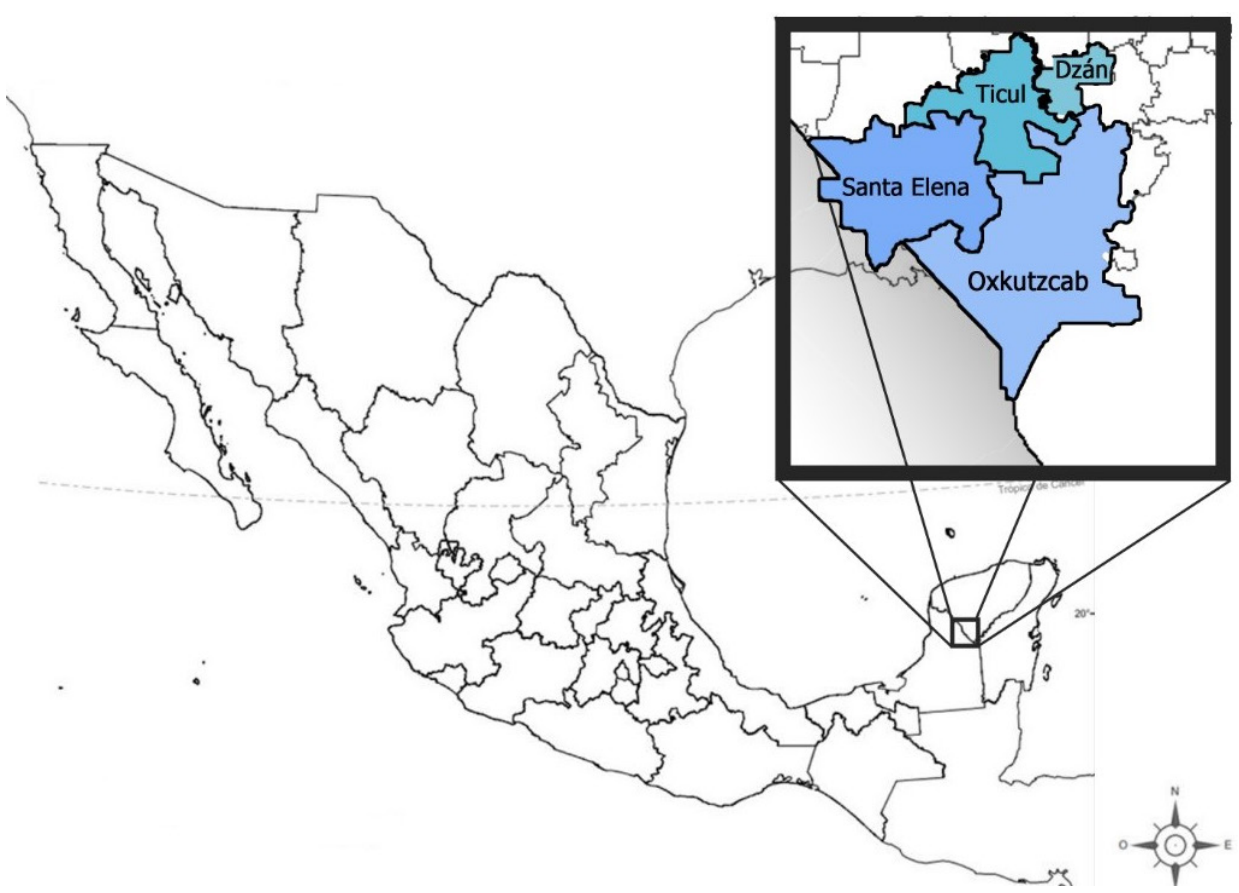

Mapa 1. Mapa Sur del estado de Yucatán: municipios de Santa Elena, Oxkutzcab, Ticul y Dzán. Elaborado por Óscar Nieto Villegas. 
Cabe mencionar que para el desarrollo de este trabajo elaboramos, entre los estudiantes e investigadores ${ }^{1}$, "diarios tecnológicos" como una forma de acercarnos desde sus propias narrativas al uso cotidiano de los dispositivos, para ello exploramos las prácticas de uso en los jóvenes de la región. Conjeturamos además que tales prácticas parecen estar determinadas tanto por el contexto institucional educativo, como por la necesidad de comunicación para establecer o conservar algún tipo de vinculación afectiva con los padres o familiares que emigraron y se asentaron de manera definitiva en Estados Unidos. En la conclusión elaboramos comentarios acotados sobre los diferentes usos y prácticas tecnológicas de docentes y alumnos.

\section{Remesas e índice de intensidad migratoria (IAIM)}

En el presente apartado se anotarán breves datos sobre el envío de remesas a los cuatro municipios citados, como una forma de dar cuenta de la presencia de recursos económicos remitidos por los emigrantes.

Para 2016, Yucatán recibió 142.8 millones de dólares (mdd) desde Estados Unidos. Mérida, capital del estado, percibió $53.2 \mathrm{mdd}$, lo cual representa 37.2\% del total. Por su parte, Oxkutzcab acogió 15.1 mdd (10.6\%), Tekax 14.1 mdd (9.9\%), Ticul 11.4 mdd (8\%) y Peto 11.1 mdd (7.8\%), es decir $36.6 \%$ de remesas se hicieron efectivas en la zona del Puuc ${ }^{2}$.

En cuanto al Índice de intensidad migratoria a nivel estatal ${ }^{3}$ valga señalar lo siguiente: Oxkutzcab ocupa el segundo lugar, poco más de 15\% de los hogares tienen familiares en Estados Unidos. Santa Elena se ubica en cuarto lugar, alrededor de $14.89 \%$ de las viviendas reciben remesas. Dzán ocupa el quinto lugar, entre 2010 y 2015, aproximadamente $11 \%$ de los hogares cuentan con algún pariente en «el Norte». En contraste, Ticul se encuentra en la posición 20 a nivel estatal, solo $4 \%$ de los hogares perciben remesas.

Al respecto, Ángel Basto Blanco (2015), subdirector de Atención a Migrantes del Instituto para el Desarrollo de la Cultura Maya del Estado de Yucatán (Indemaya), señala que por el tamaño de la población, Mérida es el principal expulsor de migrantes, pero el impacto es mucho mayor en municipios como Oxkutzcab donde al menos

1 Desde hace una década, el doctor Vicente Castellanos y quien suscribe el presente texto venimos investigando en la zona Sur del estado de Yucatán.

2 El Sur de Yucatán está integrado por 15 municipios distribuidos en la sierra del Puuc, una cordillera de pequeños cerros en esa zona de la península. Por la producción agrícola, se puede dividir en dos áreas. La primera se caracteriza por la citricultura, cuya cosecha se comercializa en el mercado de Oxkutzcab. Mientras que en la segunda, la siembra y el cultivo del maíz son importantes a nivel estatal.

3 El Anuario de Migración y Remesas 2017. CONEVAL. México. 
la tercera parte de sus habitantes están en San Francisco, California o en Portland, Oregon.

La migración es el aspecto central para Oxkutzcab, Santa Elena y Dzán, ya que se encuentran dentro de los cinco primeros lugares a nivel estatal en intensidad migratoria hacia Estados Unidos, mientras que Ticul está en el número diez.

En el caso de las remesas, casi $40 \%$ de los envíos que llegan a Yucatán tienen como destino el Sur del estado; en este punto, es importante destacar que no hay cifras exactas de remesas para Dzán y Santa Elena, puesto que son municipios pequeños y es probable que las cobren en localidades como Oxkutzcab o Ticul.

A continuación, presentamos los principales municipios por índice de intensidad migratoria.

\section{Principales municipios por Índice Absoluto de Intensidad Migratoria (IAIM)}

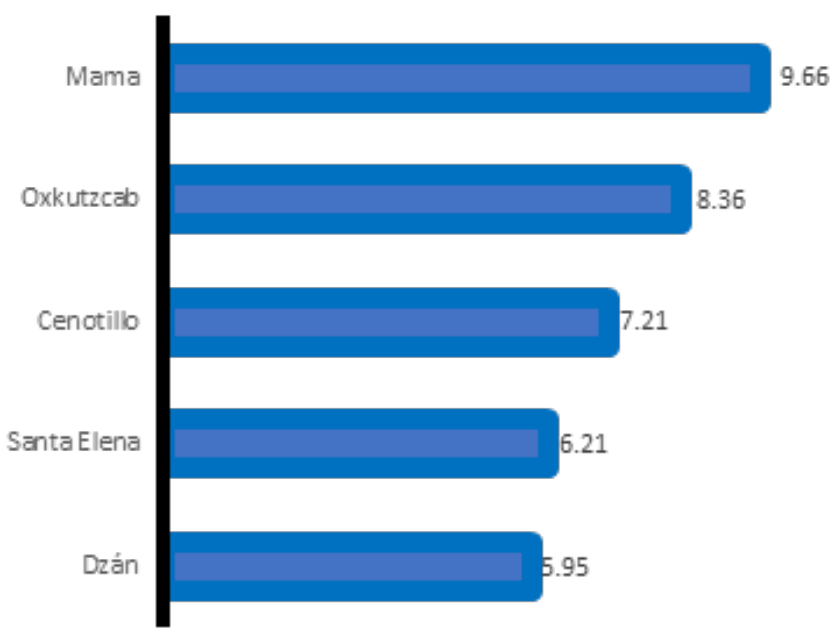

Fuente: Fundación BBVA Bancomer A. C. y Conapo (2017)

\section{Población y niveles de pobreza en el Sur de Yucatán}

Para comprender y dimensionar las características del Sur del estado es necesario dar cuenta de algunos de los indicadores socioeconómicos de la población en Dzán, Oxkutzcab, Santa Elena y Ticul.

A pesar de las remesas, la pobreza y el rezago disminuyen de forma lenta, grandes porcentajes de la población de los municipios presentan carencias en indicadores del Consejo Nacional de Evaluación de la Política de Desarrollo Social (Coneval). 


\section{Dzán}

La Encuesta Intercensal 2015 indica que hay 5 mil 357 habitantes en Dzan, de los cuales, 2 mil 638 son hombres y 2 mil 719 son mujeres; se estima que $69.24 \%$ de la población mayor a tres años es maya hablante.

El Informe Anual sobre la Situación de Pobreza y Rezago Social 2015 revela que $29.7 \%$ de la población se encontraba en pobreza extrema, $49.9 \%$ en pobreza moderada; de tal forma que $79.6 \%$ de los habitantes tenía carencias en el acceso a bienes y servicios básicos. Más de la mitad de la población mayor a 15 años presenta nivel escolar básico incompleto. El municipio sigue siendo una Zona de Atención Prioritaria Rural ${ }^{4}$ por su alto nivel de marginación y rezago social.

\section{Oxkutzcab}

La población de Oxkutzcab es de 31 mil 202 personas, de las cuales 15 mil 32 son hombres y 16 mil 170 son mujeres; se estima que aproximadamente $60.42 \%$ son mayahablantes (Encuesta Intercensal 2015).

Por otro lado, en el Informe Anual sobre la Situación de Pobreza y Rezago Social 2015 muestra que $72.9 \%$ de la población está en condiciones de pobreza.

\section{Santa Elena}

La Encuesta Intercensal 2015 indica que la población de Santa Elena es de 4 mil 47 personas, de las cuales mil 999 son hombres y 2 mil 48 son mujeres, se estima que $78.49 \%$ son bilingües de lengua maya y español, y $4.26 \%$ son monolingües mayas.

El Informe anual sobre la Situación de Pobreza y Rezago Social 2015 indica que 79.9\% de la población estaba en condición de pobreza.

\section{Ticul}

De acuerdo con la Encuesta Intercensal 2015, Ticul tiene una población de 40 mil 161 habitantes; de los cuales 19 mil 726 son hombres y 20 mil 435 son mujeres; se estima que $40.10 \%$ son hablantes de lengua indígena.

El Informe anual sobre la Situación de Pobreza y Rezago Social 2015 indica que $61.8 \%$ de la población se encuentra en situación de pobreza y $12.8 \%$ del total de los habitantes en pobreza extrema.

Ticul se caracteriza además por dos actividades económicas. La primera, la citricultura pues aparece junto con Oxkutzcab, Dzán, Santa Elena como uno de los principales

4 «Zonas de Atención Prioritaria Rurales: mil 115 municipios que se encuentran en 24 entidades federativas y que cumplen con alguna de las siguientes condiciones: son de Muy Alta o Alta Marginación o tienen Muy Alto o Alto Grado de Rezago Social o el porcentaje de personas con al menos tres carencias es mayor o igual al 50\%» (Diario Oficial de la Federación (DOF), 2016) 
productores de la zona (Secretaría de Agricultura y Desarrollo Rural, 2012) ${ }^{5}$. La industria zapatera es el segundo motor económico del municipio. El estudio La industria del calzado de Ticul, un panorama hacia la competitividad (2015) destaca que de las 519 unidades económicas registradas, 312 se dedican a la actividad zapatera con una producción anual de 453 mil 600 pares de calzado.

\subsection{Educación en la zona Puuc}

Uno de los indicadores de mayor rezago en los municipios analizados es el educativo. En Dzán, Oxkutzcab y Santa Elena más de la mitad de la población mayor a 15 años tiene educación básica trunca; en contraste, Ticul presenta $43 \%$.

\section{Dzán}

En este municipio no existe institución de educación media superior o bachillerato, por lo que los jóvenes deben ir a Ticul, Oxkutzcab o Santa Elena para continuar sus estudios.

Hay 270 jóvenes de entre 15 y 17 años, de los cuales 69\% asiste a la escuela (Inegi, 2015). En este sector, que corresponde con el nivel medio superior, hay una deserción considerable con respecto a la educación básica.

\section{Oxkutzcab}

Para la educación media superior se cuenta con cuatro bachilleratos, dos públicos, la Preparatoria Víctor Manuel Cervera Pacheco y el Centro de Bachillerato Tecnológico Agropecuario, y dos privados, la Preparatoria Oxkutzcab y el Instituto Arcadio Santoyo. La población de entre 15 y 17 ańos, que corresponde a este nivel educativo, es de mil 911 personas, de las cuales, $62.74 \%$ asiste a la escuela. Se observa que en el nivel medio superior hay una deserción considerable.

En 1999, el Instituto Tecnológico Superior del Sur del Estado de Yucatán (ITSSY) inició actividades educativas. Durante el periodo 2016-2017 la matrícula del ITSSY era de mil 42 alumnos inscritos; del total de estudiantes, $66.5 \%$ eran hombres y $33.5 \%$ mujeres. Actualmente dicho Instituto tiene una zona de influencia que abarca $22 \mathrm{mu}$ nicipios del Sur y Sur poniente del estado ${ }^{6}$, cuenta con oferta académica de cinco ingenierías: Industrial, Bioquímica, Sistemas Computacionales, Gestión empresarial y Desarrollo comunitario ${ }^{7}$. La gran mayoría de jóvenes asiste a esta institución educativa como una alternativa viable para continuar su formación escolar.

5 Antes Secretaría de Agricultura, Desarrollo Rural, Pesca y Alimentación (Sagarpa).

6 Abalá, Akil, Cantamayec, Chapab, Chacsinkin, Chumayel, Dzán, Mama, Maní, Mayapan, Muna, Sacalum, Santa Elena, Teabo, Tekit, Tekax, Ticul, Oxkutzcab, Peto, Thadziú, Tekax, Tixmehuac y Tzucacab

7 Instituto Tecnológico Superior del Sur del Estado de Yucatán (consultado el 8 de marzo de 2017) 


\section{Santa Elena}

Para el caso del nivel medio superior, el municipio cuenta con el plantel del Colegio de Bachilleres del Estado de Yucatán (COBAY) y el Telebachillerato Comunitario. De acuerdo con el Inegi (2015), hay 268 personas de entre 15 y 17 ańos, correspondientes a este nivel educativo, de las cuales, $62.31 \%$ asiste a la escuela. Casi $40 \%$ no cursan estos estudios.

\section{Ticul}

Cuenta con cinco bachilleratos y 13 escuelas de formación para el trabajo. En cuanto a educación superior, destaca el Centro Educativo Rodríguez Tamayo, instituto privado que inició hace veinte años y ofrece primaria, secundaria y preparatoria, así como ocho licenciaturas y una maestría. De igual forma, se encuentra la Escuela Normal de Ticul. De 2 mil 102 personas de entre 15 y 17 ańos, 75\% asiste a alguna institución educativa

Otra característica que comparten Dzán, Oxkutzcab y Santa Elena es que son consideradas Zonas de Atención Rural, es decir presentan importantes rezagos en cuestión de acceso a la salud, educación y servicios para la vivienda; si bien, los tres mostraron un avance considerable de 2000 a 2015 el rezago más importante es en el aspecto educativo, pues más del 50\% de la población mayor de 15 años tienen educación básica inconclusa. En el caso de Ticul esta cifra es menor. En términos de oferta escolar, Oxkutzcab y Ticul cuentan con los centros educativos más importantes de la zona.

\section{Jóvenes y tecnologías de la información comunicación (TIC)}

Para desarrollar una aproximación a las prácticas de uso de las tecnologías (TIC) por parte de los jóvenes yucatecos, valga revisar puntuales conceptos que permitan abordar dicho uso. Las prácticas han sido estudiadas por los científicos sociales desde diferentes perspectivas y enfoques por lo que en la literatura especializada se las define con distintas denominaciones como prácticas culturales, comunicativas o sociales; cabe destacar que más que ser opuestas o contradictorias, se complementan y permiten entender el quehacer de las personas en el todo social.

Así, el concepto de prácticas culturales postula «una idea de proceso, de acción que cambia constantemente para resignificarse en su relación con el tiempo y el espacio» (Itchart y Donati, 2014: 18). En este sentido, Mary Uribe (2014), apunta que en la vida cotidiana el sujeto discurre de forma normal y corriente con relación a un contexto específico donde construye relaciones sociales compartidas.

Para Valencia y Magallanes (2015), las prácticas comunicativas están vinculadas con esfuerzos de crear, transformar, recuperar y conservar sentidos, redes y lazos para promover alternativas frente a un orden social injusto y excluyente. 
Por su parte, Orozco (1998) señala tres dimensiones esenciales para comprender una práctica social. La primera es la socialidad, entendida como la dimensión interpersonal y colectiva "que se inspira y orienta en otras racionalidades como la de los afectos, la del poder, la de la lucha [...] es una trama que pone en la escena de lo cotidiano diferentes actores en su lucha por sobrevivir, relacionarse y mantener su identidad» (p. 6). La segunda dimensión es la ritualidad, que se entiende como una permanencia que va más allá de lo espontáneo de la comunicación y que confiere a la práctica ese carácter; el autor señala que, aunque la ritualidad implica un mecanicismo y repetición, también conlleva a la creatividad y reflexión, pues las situaciones en las que se da nunca son iguales. Finalmente, la tecnicidad no se refiere solamente a lo instrumental (los dispositivos o medios de comunicación), sino a los nuevos procesos y reflexiones que se generan a partir de dichos instrumentos; Orozco insiste que la comunicación no está determinada por los medios; para el autor, aceptar que «el medio es el mensaje» es reconocer que no hay comunicación fuera o externa a los medios.

También es pertinente añadir la dimensión espacio temporal, que hace referencia a los lugares, ritmos, periodos o velocidades en las que se pueden o deben realizar determinadas acciones (Grimson, 2001). Por ejemplo, los horarios y momentos pertinentes para utilizar o comunicarse a través de la computadora o el celular (prohibiciones, reglas o normas familiares y escolares); debido a la interacción con los otros, las prácticas sociales y culturales están en constante cambio, negociación y reelaboración.

En cuanto a la relación entre los jóvenes y las tecnologías, gran parte de los estudios se han centrado en explorar la inserción de estas en los ámbitos educativos formales, así como en evaluar el uso o abuso que se hace de ellas fuera de dicho ámbito. Otros análisis han abordado las ventajas y los riesgos que conlleva el uso de las TIC en la vida diaria, incluso han desarrollado guías educativas para jóvenes y padres de familia sobre las ventajas y los riesgos al usarlas

Para Alvarado y Pinilla (2017) las tecnologías de la comunicación posibilitan diferentes formas de participación en función de las necesidades particulares de los individuos y grupos; de tal modo que no se puede esperar que cada tecnología o plataforma sea utilizada y aceptada por igual. Según los autores citados hay dos tipos de prácticas de uso, el propuesto por los proveedores de los dispositivos tecnológicos (empresarios, autoridades y científicos) y el uso real que se hace de ellas.

El primero se refiere al uso operativo, es decir, al empleo básico para enviar un mensaje, realizar una llamada o bajar alguna aplicación; mientras que el segundo alude a la forma en la que los actores intervienen las tecnologías, cómo construyen nuevas maneras de estar en los espacios virtuales a su alcance (Cardón, 2005).

En este sentido, De Certeau (2000), Cardón (2005) y Alvarado y Pinilla (2017) destacan la dimensión participativa, activa y creadora que tienen los sujetos en función de sus necesidades particulares; para los investigadores mencionados, en la innovación 
o transformación de las prácticas se visibilizan las verdaderas necesidades de comunicación o información de los usuarios.

Greenhow y Lewin (2016) afirman que las tecnologías permiten a los jóvenes mantenerse comunicados, entretenerse, pero también posibilitan el aprendizaje en distintos ámbitos; así plantean que éste va más allá de la concepción binaria formal-informal, pues tiene atributos formales, no formales e informales los que suelen estar determinados por el contexto y las situaciones específicas. Señalan además que la tecnología tiene el potencial de disrumpir en las fronteras de los espacios donde se lleva a cabo el aprendizaje, pues permite que los estudiantes formen comunidades y participen de diferentes maneras (compartiendo, publicando, comunicando, administrando e interactuando entre sí), y posibilitar el acceso a recursos y competencias con las cuales se vuelven coproductores de prácticas y conocimientos.

Los autores citados también aseveran que las escuelas no tratan a los jóvenes como si tuvieran conocimientos, emociones, aspiraciones, sentimientos y voluntad propia, sino como destinatarios del conocimiento de los adultos; por ello existe una distancia muy amplia entre las formas de usar la tecnología dentro de la escuela y fuera de ella. (Pereira, Fillol y Moura, 2019).

Fernández (2002) reitera lo anterior cuando afirma que hay un desajuste entre la sociedad y la escuela, ya que la institución no parece responder a las necesidades de la sociedad del conocimiento. Es decir, hay un desfase de la educación formal con respecto a los cambios tecnológicos experimentados por los estudiantes, pues la cultura propuesta por la institución tiene cada vez menos que ver con la que viven los jóvenes fuera del ámbito escolar.

En este sentido, Silva (2008) ratifica que la escuela sigue cerrada en sí misma y en sus rituales de transmisión de información; permanece ajena de prácticas educativas que incorporen la participación e interacción del estudiantado acostumbrado a una pantalla multiforme, polifónica, polisémica; no ha implementado prácticas capaces de tratar a los alumnos tal y como ellos son, activos, autónomos, independientes y con autoría propia.

Como se echa de ver, los educadores deberían beneficiarse del aprendizaje y las competencias tecnológicas que los estudiantes han adquirido dentro y fuera del salón de clase. Asimismo, la institución educativa habría de apropiarse e introducir dichas herramientas tecnológicas en el aula; también debería de orientar el uso hacia fines educativos, integrando los nuevos medios, sus símbolos y recursos.

\subsection{Jóvenes rurales y TIC}

Sobre la juventud rural e indígena y el uso de las tecnologías, son todavía pocos los estudios que han abordado el tema. Un ejemplo para mencionar es el de María Elisa 
Fornasari (2014), quien exploró las formas de apropiación de las TIC en una comunidad rural en Argentina.

La autora identificó dos grupos de jóvenes; en primer lugar, los estudiantes, cuyos usos son más colectivos y entre pares, enfatizando las redes sociales y los usos enfocados a sus tareas escolares; en segundo lugar, los jóvenes independientes, padres de familia o trabajadores, quienes expresan usos más individuales y relevantes para sus actividades laborales o de crianza, como hacer reportes o las tareas de sus hijos.

Además, señala que, aunque las fronteras entre el campo y la ciudad son cada vez más borrosas debido a la diversificación e intercambio de actividades, cada uno tiene sus particularidades en cuanto a la apropiación de las TIC. La primera de ellas es geográfica, tiene que ver con la ubicación y conectividad, pues en las zonas rurales hay más limitantes de infraestructura que en la ciudad. La segunda se relaciona con las características culturales y específicamente con el lugar que ocupan los jóvenes en las actividades de la familia.

De modo que para Fornasari, los jóvenes se vinculan con la tecnología según pautas propias que construyen intersubjetivamente con sus pares, pero que están mediadas por instituciones que organizan las prácticas, como es el caso de la familia o la escuela.

Si se prolonga esta breve revisión con los jóvenes yucatecos, encontramos tres abordajes principales: jóvenes migrantes, jóvenes de origen yucateco en Estados Unidos y jóvenes no migrantes. A continuación, los describimos de forma que podamos reconocer cómo ha sido problematizada la juventud de la entidad, considerando que gran parte de los entrevistados sostiene que si bien en el hogar se habla la lengua maya, ellos y ellas aseguran que la entienden, pero no la suelen utilizar para comunicarse de forma cotidiana.

Uno de los temas explorados en años recientes ha sido el de jóvenes migrantes y retornados; Cornejo (2016) señala que, aunque en estudios previos no se analizaba de manera particular a los jóvenes como parte de los procesos migratorios, se demostró que estos sectores eran agentes importante para la transformación de sus comunidades. Al respecto, Olvera (2016) destaca a la juventud migrante como protagonista del desarrollo comunitario y de la transformación de la ruralidad yucateca.

Para el autor, la migración de jóvenes de Mama, Yucatán, hacia Estados Unidos tiene un efecto no solo en el que la vive, sino también en su familia y en toda la comunidad, pues este fenómeno ha permitido que se edifiquen más viviendas, se implementen servicios y que aquellos jóvenes que no migraron tengan acceso a herramientas tecnológicas que les permitan conocer formas de vida diferentes a la suya.

Del mismo modo, Estrella (2014) aborda el papel de los jóvenes migrantes de Tunkás, Yucatán, para la transformación de las dinámicas de la comunidad, pues la migración les permite, por un lado, reunir dinero para comprar un terreno, una casa, un auto o iniciar un negocio; pero también, posibilita conocer códigos culturales diferentes 
a los de su comunidad. Sobre este punto, el autor destaca que al volver al terruño, lo retornados entran en contacto con los jóvenes no migrantes, a quienes les comparten los elementos culturales adquiridos mientras estaban en Estados Unidos.

El segundo tipo de abordaje es el de los jóvenes de origen yucateco en Estados Unidos; Casanova (2016) explora las formas de aculturación (adaptación) y las transformaciones identitarias, pues son necesarias para entender la experiencia migratoria y las necesidades de este sector, pero también para ver de qué forma los jóvenes resignifican el ser maya en el país del norte. La autora indica que los jóvenes asocian el lenguaje, las tradiciones y las costumbres con lo maya y se sienten orgullosos de su origen; sin embargo, ven en Estados Unidos oportunidades educativas y laborales que les permitan tener una mejor vida que la de sus padres.

El tercer abordaje es el de los jóvenes no migrantes; en párrafos anteriores se mencionó que la migración ha tenido un efecto transformador en la ruralidad yucateca; esta situación ha beneficiado a los no migrantes, quienes tienen acceso a herramientas tecnológicas como los teléfonos inteligentes y las computadoras, pero también servicios como el internet que les permite conocer hábitos, culturas, lugares e ideas diferentes a las locales (Olvera, 2016).

Estrella (2014) reitera que, al migrar y retornar de Estados Unidos, los jóvenes adquieren códigos culturales diferentes a los de su comunidad y, posteriormente, los comparten con los no migrantes; de tal modo que, estos últimos, además de las competencias que desarrollan a través de las tecnologías, aprenden de las experiencias y prácticas de sus pares. El autor indica que los migrantes exitosos, es decir, aquellos que lograron sus metas (ahorraron, edificaron una casa, compraron un vehículo o iniciaron un negocio) se vuelven figuras a seguir para los jóvenes no migrantes; de tal modo que se genera un choque entre adultos y jóvenes, pues los primeros no aprueban ciertos códigos verbales y no verbales (como la vestimenta, la forma de hablar y de comportarse); sin embargo, estas apropiaciones culturales sirven como estrategia para visibilizarse frente a otros grupos de la sociedad.

Sobre el tema, también cabe mencionar a Ismael May May (2010), quien explora el uso de la maya a través del chat como forma de mantener el contacto entre mayahablantes migrantes en Estados Unidos y su familia en el lugar de origen; con este trabajo, el autor señala que los nuevos medios reivindican la práctica de la lengua a través del uso cotidiano.

Este breve resumen representa el papel que los jóvenes y la migración han jugado como factor de cambio para los municipios del Sur de Yucatán (Oxkutzcab, Dzán, Santa Elena); no obstante, la juventud no migrante también aporta en dichos cambios. Como no migrantes tienen a su alcance herramientas, competencias e información que les permiten vivir experiencias que están fuera de su municipio o localidad. 


\subsection{Propuesta metodológica: trabajo de campo y diarios tecnológicos}

En este proyecto colaboramos con ocho profesores de las materias de Informática, Computación y Competencias Digitales y con 66 jóvenes estudiantes de cuatro secundarias y cinco preparatorias en los municipios en estudio. A continuación, presentamos la síntesis del trabajo de campo (instrumentos aplicados, jóvenes y docentes entrevistados) ${ }^{8}$ llevado a cabo entre febrero y septiembre de 2016.

\begin{tabular}{|l|l|l|l|l|}
\hline Municipio & Nivel educativo & Jóvenes & $\begin{array}{c}\text { Diarios } \\
\text { Tecnológicos }\end{array}$ & Profesores \\
\hline Dzán & & 5 & & \\
\hline \multirow{2}{*}{ Oxkutzcab } & Secundaria & 10 & 4 & 4 \\
\cline { 2 - 5 } & Bachillerato & 18 & 18 & 1 \\
\hline \multirow{2}{*}{ Santa Elena } & Secundaria & 4 & 4 & \\
\cline { 2 - 6 } & Bachillerato & 9 & 9 & 1 \\
\hline \multirow{2}{*}{ Ticul } & Secundaria & 6 & 6 & 1 \\
\cline { 2 - 5 } & Bachillerato & 14 & 14 & 1 \\
\hline Total & & 66 & 55 & 8 \\
\hline
\end{tabular}

Las entrevistas se realizaron en las escuelas, pues es el espacio que reúne a los jóvenes y en el que conviven con sus pares. Los estudiantes fueron elegidos al azar por sus profesores, pero al final cada uno decidía si quería participar en las actividades o no. En este punto, reconocemos que la institución tenía un peso muy fuerte pues en su mayoría se comportaron como si estuvieran en alguna de sus clases.

La idea del diario tecnológico surge como una propuesta en la que pedimos a los jóvenes que, a modo de diario, relataran qué hacían con la tecnología a lo largo de la semana o contaran alguna situación en la que las tecnologías les habían ayudado a resolver algún problema o duda de su vida diaria. Aunque era una actividad pautada, tenían la libertad de narrar con su puño y letra y sus propias palabras el papel que ocupan las tecnologías en su vida diaria. Respecto a los profesores, las entrevistas fueron individuales y, en algunos casos, en pareja. Se abordó el tema de la inserción de las TIC en el aula y qué estrategias y retos identificaban al respecto.

8 Los instrumentos de investigación fueron la entrevista semiestructurada y los diarios tecnológicos. La investigación de corte cualitativo nos permitió acercamos a los jóvenes yucatecos a través breves narrativas que ellos y ellas elaboraron. Para profundizar sobre el tema véase Castellanos (2019), "Construir conocimiento en diálogo: Ruta Puuc. Jóvenes y tecnologías en Yucatán» en Cornejo y Giebeler (2019). Prójimos. Prácticas de investigación desde la horizontalidad. 


\section{3. ¿Qué hacen los jóvenes yucatecos con las tecnologías?}

Como primera expresión de los diarios tecnológicos y entrevistas realizadas en el Sur de Yucatán, encontramos diferentes usos de las tecnologías que se dan en función de sus actividades y necesidades diarias. Identificamos cuatro tipos de prácticas de uso: con fines escolares, con fines de ocio, con fines comunicativos y el uso exploratorio para el beneficio propio.

Las prácticas de uso con fines escolares se dan en el marco de la educación formal, es decir, dentro de las actividades y responsabilidades académicas, tienen un carácter obligatorio, pautado y normado. Con estas prácticas, los jóvenes siguen indicaciones de los profesores para aprender a usar algún programa, realizar una tarea o investigar cierto tema. Ellos y ellas mencionaron que en las clases de computación y tecnologías les enseñaban a usar procesadores de texto, hojas de cálculo o realizar presentaciones, pero también a implementar búsquedas de información.

Todo el tiempo me puedo conectar, si en la escuela hay alguna duda, a veces el mismo profesor 'ah, necesitamos que busquen esto' agarro mi teléfono, texteo y ya me aparece la definición (Abner, 17 años, Dzán).

También encontramos que, de forma independiente, los estudiantes buscaban información para diferentes materias, consultar dudas en internet y para complementar o corroborar los trabajos de las asignaturas. De igual manera, se ponían de acuerdo para la realización de tareas o proyectos escolares.

Estos días nos hemos hablado por los grupos de WhatsApp para ponernos de acuerdo que nos juntemos a estudiar (Eric, 15 años, Ticul).

El lunes que vine a la escuela utilicé mi celular para entrar a Google Translator y hacer una tarea (Alejandra, 15 ańos, Ticul).

El día martes la profesora Guadalupe marcó un trabajo de investigación y pues no me daba abasto los libros, así que tuve que recurrir a Google para buscar información que me sirviera. El día miércoles el maestro Enrique me marcó un ejercicio, bueno, pues era de equipo, consistía en buscar una obra de teatro así que entré a Google, la busqué y me parecía muy interesante y tuve la idea de entrar a YouTube para buscar la puesta en escena y ahí estaba, así que la descargué y pues me sirvió de mucho (Daniel, 17 años, Santa Elena). 
Me encontraba con una duda en mi libro de matemáticas. Existían ciertas palabras, las cuales no sabía sus significados. Le pregunté a algunas personas sobre esto y me dijeron que no sabían su significado, estaba preocupado ya que por estas palabras no comprendía el texto el cual tenía ejercicios para realizar, así que decidí buscar los significados de cada palabra en mi celular. Una vez encontrados, logré entender el tema y pude realizar mis trabajos (José, 16 años, Ticul).

Si bien, el uso de la tecnología para llevar a cabo actividades escolares está condicionado por las instrucciones del profesor, también se observa la iniciativa de los jóvenes para explorar y complementar el aprendizaje con videos de YouTube.

Las prácticas de uso lúdicas o con fines de ocio son las que se efectúan en el tiempo libre, cuando los jóvenes han terminado sus tareas escolares y quehaceres en sus hogares; en este punto destacan los videojuegos y el uso de redes sociales.

Yo uso la tecnología para ver videos, hacer tarea, pero mayormente la utilizo para jugar en línea con otras personas. Cuando veo videos sobre juegos o tareas aprendo mucho sobre el tema (José, 15 años, Oxkutzcab).

Los martes, miércoles, jueves y viernes son lo mismo, la única diferencia es que en mi celular busco a mis Youtubers favoritos y suben videos nuevos (Abraham, 14 años, Santa Elena).

Puedo hacer muchas cosas como chatear, jugar juegos o en el caso del Facebook puedo ver publicaciones y en Google leer informaciones (David, 14 años, Santa Elena).

La mayoría de este tiempo la he usado también para entretenimiento propio, viendo videos, escuchando canciones, leyendo alguna noticia (Faridy, 17 años, Ticul).

El viernes yo había hecho un dibujo y con un programa que tenía en mi computadora (Paint Tool Sai), y pinté la imagen y al terminar la puse en mi muro que tengo en Youtube y el sábado y domingo no agarré ninguna tecnología (Sayuri, 14 años, Oxkutzcab).

Los jóvenes yucatecos reconocen que las actividades escolares están en primer plano, pues en gran parte de las entrevistas y diarios destacan que jerarquizan el resto de dichas actividades con base en las escolares. Observamos que las prácticas de ocio en las tecnologías son diversas, durante el tiempo libre ven videos en YouTube, escuchan música, juegan en diferentes dispositivos, se conectan en Facebook para interactuar con otros.

Las prácticas de uso con fines comunicativos son aquellas que los jóvenes realizan para interactuar con los otros. Identificamos dos niveles de la interacción a través de las 
tecnologías; el primero de ellos es el local y se da principalmente entre pares y con los familiares que viven en la comunidad.

A veces uso WhatsApp para platicar con mis compañeros o hacer planes para hacer algo o abrir las redes sociales [...] algunas veces subo fotos (Jahir, 14 años, Oxkutzcab).

El segundo nivel de interacción es hacia afuera de la comunidad y se da principalmente con familiares que viven en Estados Unidos; durante las entrevistas la mayoría de los jóvenes señalaron que tienen a algún pariente en Estados Unidos, con quien tienen contacto permanente a través de WhatsApp y las videollamadas por Skype o Messenger.

Estoy bien aquí, mi papá está en Estados Unidos [...] hace como 14 años [se fue y no viene] hablo con él cada domingo, porque lo veo por Messenger, [se siente] bien, porque lo estoy viendo, estoy viendo que prácticamente está más mejor, está viviendo bien (Luci, 18 años, Oxkutzcab).

Mi papá está en Estados Unidos [...] ahorita tengo comunicación con él, a veces solo me llama y platico un rato, me dan ganas de estar ahí, al principio como que te sientes rara porque digamos que es como un desconocido; pero ya luego como que le agarras la confianza y ya (Sandra, 16 años, Oxkutzcab).

Me siento bien, porque casi nunca veo a mis familiares y es bueno hablar con ellos [...] mis tíos cada quien tiene su Facebook y me manda mensaje y así hablamos (María, Fernanda, 13 años).

Me siento feliz, pues ahorita, pues quizás no puedan estar físicamente, pero como ya hay muchos avances, pues hay videollamada y pues ya puedo saber un poco más de ella. (Faridy, 17 años, Ticul)

Me siento feliz, bien, porque incluso por las videollamadas pues puedes ver, verlo físicamente, como si estuvieras platicando con él en persona, pero no está (Carlos, 16 años, Ticul).

En menor medida apareció el contacto con desconocidos a través de las redes sociales

Conocí a un amigo de la India y me agregó a un grupo raro, Usain se llama; y casi no entiendo lo que me dice, nada más veo sus fotos, por lo que dicen, como árabe, no entiendo [...] es bonito, me gusta y aparte como sé inglés hablo con ellos en inglés y entendemos y me gusta (Juan Carlos, 22 años, Oxkutzcab). 
En el caso del contacto con extraños a través de redes sociales se abren interrogantes sobre las prácticas que generaría y los riesgos que podría representar.

Se observa que la comunicación en lo local tiene mucho que ver con la planeación u organización de reuniones, visitas o trabajos; mientras que con la familia que está fuera del municipio los jóvenes mantienen el vínculo, aunque se percibe la nostalgia en fragmentos como «a veces solo me llama y platico un rato, me dan ganas de estar ahí» o «pues quizás no puedan estar físicamente, pero como ya hay muchos avances, pues hay videollamada y pues ya puedo saber un poco más de ella».

Finalmente, las prácticas de uso exploratorio para el beneficio propio son las que hacen los jóvenes de forma independiente y autodirigida para resolver emergencias en casa.

La semana pasada estaba ayudando a mi papá a limpiar el patio cuando mi hermana estaba desesperada, fui a ver qué le sucedía y me di cuenta de que uno de mis gatos estaba en muy mal estado, tenía mucha lagańa y le costaba trabajo ponerse de pie y como era sábado no había veterinarios disponibles. Entonces encendí la computadora e investigué los síntomas que tenía mi gato, resultó ser que tenía una especie de conjuntivitis felina y si no le dábamos medicamentos su enfermedad empeoraría. Al saber qué le sucedía a mi gato, investigué cómo tratar la enfermedad con remedios caseros y así pude reducir sus síntomas. Al día siguiente lo llevamos a consultar a la veterinaria más cercana (Carlos, 16 años, Tícul).

Pero también las utilizan para realizar alguna actividad fuera de la escuela, como crear manualidades, aprender a tocar algún instrumento musical, hacer edición multimedia, entre otras.

En mis tiempos libres me gusta [saber] sobre las culturas, las diferentes culturas, entonces yo fui, me puse a investigar acerca de eso; está la cultura maya, sobre todo lo que nos rodea (Oscar, 16 ańos, Oxkutzcab).

El día lunes me fue muy útil el celular ya que lo utilicé para ver un video en YouTube sobre cómo hacer un rosario con hilos y cuentas. Al igual que vi cómo hacer una cruz para un llavero con los mismos materiales, al verlo lo compartí con mis amigos para poder hacer llaveros y regalar para algún evento (Dayra, 17 años, Santa Elena).

Tengo un canal en YouTube, me dedico a hacer videos en la computadora. Tengo algo para editar, pero al principio usaba Viva Video, es un programa, igual ahí lo editaba y para descargar las músicas de fondo estaba navegando por YouTube. Es de lo que habla mi papá:'si vas a descargar algo y descargas al azar y no sabes cómo eso funciona’, pues 
me dijo que yo lo vea en YouTube. Si está aplicación sirve, veo los pulgares arriba, que me fijara bien en los comentarios, porque hay algunos que dicen que no funciona que tiene fallas, y así descargo las aplicaciones que son buenas (Sayuri, 14 años, Oxkutzcab). He visto los videos de físico culturismo porque me gusta ese deporte y por eso veo videos para aprender las rutinas que hay que hacer para estar en forma (Juan Carlos, 22 años, Oxkutzcab).

Con los programas que yo utilizo he tenido que aprender qué es un arpegio, para las notas musicales; aprenderme qué son las armonías, cómo funcionan [...] Tengo un programa con el que se puede crear una voz artificial para que cante, hay voces en bancos de voces en inglés, en español, japonés y uno en italiano y coreano; el caso es usarlos en espańol y en inglés, pero en inglés tuve que aprender e investigar cómo son las palabras (Sergio, 16 años, Oxkutzcab).

Si tienes ganas de saber de algún tema y quieres verlo o algún programa, ahí seguro lo buscas y te aparece; en cambio en la tele tienes que esperar el horario y si a veces tienes otras actividades que hacer, pues no vas a poder verlo (María, 17 años, Oxkutzcab).

Estas exploraciones para el beneficio propio son mucho más diversas que las del ámbito escolar, pues tienen que ver con los intereses personales de cada joven. Sin embargo, señalaron que sobre aspectos de salud no consultan internet y prefieren preguntar a sus papás o a algún médico. En el aspecto emocional, aseguraron que eligen hablar con algún amigo o familiar, escuchar música o reflexionar, pero buscar en internet alguna solución a sus problemas afectivos no era viable.

Se observa que las prácticas de uso de las tecnologías están determinadas en gran medida por un carácter normativo, es decir, el uso depende de las reglas que establece la autoridad. En el ámbito escolar el uso de los dispositivos está acotado por las instrucciones del profesor, por ejemplo, no usar el teléfono en clase o utilizarlo para realizar alguna actividad individual o grupal. Fuera de la escuela, los padres también tienen acuerdos como no usarlo a la hora de la comida o cuando hay una convivencia familiar.

Las prácticas que hemos revisado no aparecen de forma separada una de la otra, ni en horarios inamovibles, sino que se llevan a cabo en función de las actividades que realiza cada uno. En muchos casos los jóvenes señalaban que mientras hacen su tarea escuchan música, se toman fotos y entran a redes sociales para compartirlas.

En esta semana utilicé el celular para investigar sobre la tarea de química y de derecho y casi todos los días veo YouTube, veo videos y escucho música, además me comunico con mis amigos del salón (José Manuel, 17 años, Oxkutzcab). 
En el momento de hacerla [tarea] me gusta ponerme los audífonos y escuchar algo de música, después me siento a mensajear un rato con mis amigos y al culminar el día pongo alarma para el siguiente día (Fabiola, 16 años, Oxkutzcab).

De forma cotidiana los jóvenes del Sur de Yucatán se acompañan de las tecnologías, principalmente de sus teléfonos y, en menor medida, de las computadoras y los videojuegos. Reconocen el buen uso como aquel que deja un beneficio: comunicarse, aprender, hacer tareas. Para ellos, el mal uso son aquellos peligros con los que se encuentran en la red, tales como el acoso y el bullying.

Son de doble sentido, de doble filo, porque prácticamente hay cosas malas y cosas buenas, porque las buenas, te puede ayudar a tus tareas, puede apoyarte más, saber más; en las cosas malas, como dice ella, puedes ver acosadores, a través de internet, Facebook (Luci, 18 años, Oxkutzcab).

Las técnicas de información y comunicación, como su nombre lo dice, para comunicarnos, informarnos y utilizarlo para un bien, no para cosas malas (Fabiola, 15 años, Oxkutzcab).

\section{4 ¿Qué proponen los maestros respecto al uso de las tecnologías?}

A continuación, exploramos qué dicen los maestros respecto al uso de las tecnologías; con ello, pretendemos identificar qué retos observan y qué postura tienen, pero también qué estrategias y usos proponen a los jóvenes no solo para el ámbito escolar y sus actividades diarias.

Sobre la forma en la que los jóvenes obtienen los celulares, los profesores destacan que compran sus teléfonos con el dinero que mandan sus familiares de Estados Unidos.

No sé cuáles sean sus criterio para dárselos [...] pero muchos de ellos acá en la región donde estamos migran para Estados Unidos y, normalmente, ya tienen un tío, un papá, un hermano que les mandan sus celulares o les mandan dinero para comprarlo (Profesor Romel, 45 años, Oxkutzcab).

A veces se asoman con cada celular, que ya lo desearía yo haber tenido, ver esos muchachos da miedo andar con eso, es un celular de más de diez mil pesos, no es un celular cualquiera (Profesor Luis, 58 años, Oxkutzcab).

Los maestros señalan que una de las limitantes respecto al uso de las tecnologías en la escuela tiene que ver con la infraestructura, ya que carecen de equipamiento o acceso a internet. Sin embargo, comentan que utilizan las computadoras de los alumnos para avanzar en los planes de estudio. 
Necesitamos internet, necesitamos infraestructura, sino pues ahí sí se nos va a complicar un poquito [...] porque pues necesitamos enseñarles cómo van a poder crear sus trabajos (Profesora Andrea, Oxkutzcab).

No tenemos el equipamiento necesario para trabajar con los alumnos, no tenemos las computadoras, no tenemos lo que es el internet para poder navegar a través de él [...] formamos equipos y que ellos mismos traigan su computadora y yo les proporciono material (Profesor Tomás, Oxkutzcab).

Incluso una profesora comentó que permitió que los alumnos realizaran actividades con sus celulares, y reconoció que trabajaron bien y entregaron sus tareas de forma satisfactoria.

Esta ocasión cuando trabajé con ellos, [...] los evalué con diapositivas porque vimos PowerPoint, de hecho, los celulares tienen el programa y yo les permití que lo utilizaran [...] Empezaron a trabajar y me entregaron su actividad, lo hicieron, o sea, también es una herramienta y lo saben utilizar adecuadamente (Profesora Andrea, Oxkutzcab).

Por otro lado, un profesor seńaló que el celular está prohibido en la escuela, pues buscan evitar que se extravíen o haya cualquier otro tipo de problema, incluso no están permitidos otros dispositivos de almacenamiento en el Taller de Informática.

Está en el reglamento de la escuela que supuestamente está prohibido el celular [...] al menos que un maestro pida, hay maestros que trabajan con computadora, también hay maestros que trabajan con celulares [...] Aquí en el taller no está permitido eso, acá no les tengo permitido CD, DVD, USB, celulares, computadoras, nada, de hecho, yo doy el ejemplo no traigo la mía (Profesor Luis, 58 años, Oxkutzcab).

Sobre el aprendizaje en torno a las tecnologías, los maestros reconocieron que los alumnos tienen ciertas facilidades y conocimientos respecto a su uso; por ello, es necesario que como profesores estén actualizados para poder acompañar y dirigir las prácticas de los jóvenes.

Son nativos de la tecnología, a ellos actualmente no se les dificulta tanto, al contrario, se les facilita; de hecho, los maestros queremos estar actualizados constantemente, porque si no, ellos vienen con más aprendizaje (Profesor Romel, 45 años, Oxkutzcab).

Siento que nos hace falta un poquito más, sobre todo las tecnologías de la información, temas de actualización sobre ese detalle [...] Aparece el internet, aparecen juegos donde 
tú lo vives, veo nuevos celulares, [...] computadoras nuevas, todo lo que veo en cuestión de la robótica (Profesora Andrea, Oxkutzcab)

¿Cuál es la verdadera labor del maestro? [...] Lo primero es que tanto él como yo vamos a aprender juntos, solo que yo soy el que va a dirigir, solo que yo soy el que va a encaminar, el que va a encausar ¿¿sí? Mientras no pensemos los maestros así, todavía no somos maestros [...] porque están mal acostumbrados a que cada vez que agarran una computadora, cualquiera que sea, juegos, YouTube y nada de estudio, nada de investigación, nada de provecho (Profesor Luis, 58 años, Oxkutzcab)

De acuerdo con lo que comentan los docentes, ellos esperan que en sus clases de Informática, Computación o Competencias Digitales, los alumnos aprendan sobre la historia y componentes de las computadoras; a usar herramientas como el correo electrónico, Word, PowerPoint, Excel y utilicen internet no solo para redes sociales y diversión, sino también para adquirir competencias con miras a una carrera profesional.

Ahorita que les enseñamos cosas de Word dicen «oh, ya vimos Word», les digo "sí, vieron Word, pero no ver nomás teclear, teclear, teclear, teclear, sino que van a ver otras aplicaciones que nunca han utilizado y que les va a ser de ayuda por si siguen estudiando a un nivel superior». Pero, sí veo que cuando les hablo de partes de ciertas computadoras, no las conocen; cuando damos informática o competencias, les hablamos de la historia de la computación [...] cuando les ponemos a hacer una actividad para la casa, lo tienen que enviar a nuestro correo, eso tampoco es un uso importante para ellos; normalmente no lo utilizan (Profesor Romel, 45 años, Oxkutzcab).

Aquí en mi grupo pregunté «¿De qué manera utilizan el internet? y ¿para qué?» ellos comentaron «solamente lo utilizamos para entrar en el Facebook, para descargar música, videos y juegos», "pero ¿ustedes saben lo que es internet aparte de descargar música?, ¿saben qué más pueden hacer?» "pues creo que solo eso», «no, jóvenes, ustedes pueden, a través de él, proporcionar información ¿̨sí? ya sea de nuestro medio o de otros países (Profesor Tomás, Oxkutzcab).

Que valoren lo que son las herramientas de internet, que les den el uso adecuado, porque en ocasiones ellos entran en su Facebook, pero solamente es una plática, no saben cómo enviar un archivo por medio del Facebook o, incluso, hace unos días que les solicité que me envíen un correo, no saben cómo crear un correo, entonces, esos son los pasos que nosotros vamos a realizar con ellos (Profesor Tomás, Oxkutzcab).

Los profesores dan cuenta que, para ellos, hay un límite entre los usos adecuados e inadecuados que se pueden hacer de las computadoras, los celulares y el internet. De 
acuerdo con lo que comentan, los primeros están relacionados con los conocimientos técnicos en computación, la paquetería de Office, la búsqueda de información vinculada con actividades escolares; mientras que los segundos tienen que ver con el exceso en el uso de redes sociales, así como con la diversión.

Ellos utilizan mucho lo que son teléfonos celulares, tabletas, cosas que le dan más bien diversión o comunicación con el compañero, pero si les hablamos sobre la computación o cuestiones de computadoras se les dificulta un poquito, no están tan arraigados a eso, creen que es una tecnología ya antigua la computadora (Profesor Romel, 45 años, Oxkutzcab).

Lo que utilizan mucho es la tableta o sus celulares, pero lo que es la computadora, la utilizan muy poco, más bien, cuando lo requiere un maestro nada más, pero que lleguen a su casa y se pongan a trabajar con la computadora, una laptop, casi no (Profesor Romel, 45 años, Oxkutzcab).

Ellos básicamente lo usan más para la diversión o su pasatiempo. A un joven ahora, si le das por ejemplo un celular, se puede pasar una, dos, tres horas utilizándolo y tal vez se olvida de lo que es una plática directa con su padre, con un maestro o hasta sus propios compañeros; por eso digo que hay que enseñarles para qué les va a servir la tecnología, orientarlos un poco, decirles que no solo para ver videos en YouTube, pasarse también a dónde pueden buscar información valiosa (Profesor Romel, 45 años, Oxkutzcab).

A pesar de los retos que identifican los profesores, también reconocen que los jóvenes tienen cierta facilidad para usar las tecnologías y eso les será de utilidad.

Ayer estaba platicando con mi grupo en cuestión de tecnología de punta, les comentaba a ellos, «nosotros no tenemos la tecnología de punta aquí en nuestra institución, de hecho muchas escuelas no lo tienen, podemos decir que Estados Unidos sí lo tiene, pero si nosotros tenemos esta tecnología no muy avanzada, y le damos el uso adecuado, si nosotros explotamos lo que tenemos nos va a ir bien, [...] Vamos a suponer un ejemplo, si voy a descargar un juego, será que me va a beneficiar a mí estar jugando todo el día y tengo un ejercicio de investigación por medio de internet ¿̨cuál me va a beneficiar, el jugar todo el día o hacer la investigación?», entonces ahí se ponen a analizar (Profesor Tomás, Oxkutzcab).

Para un joven es mucho más fácil hacer videos, yo siento que la tecnología para ellos les va a servir, van a rebasar los límites que hay ahorita, sí se van a tardar porque nacieron con ella. Yo veo que las aplicaciones que hay en internet para ellos es algo común 
bajarlas y las saben utilizar mucho más que la gente ya mayorcita (Profesor Romel, 45 años, Oxkutzcab).

Aunque algunos docentes expresan cierto rechazo a las tecnologías, otros son más abiertos, incluso han intentado integrar los teléfonos celulares a sus clases. Los maestros, al ser los responsables de los grupos, consideran que tienen el reto de conocer y adoptar, en la medida de lo posible, las dinámicas interactivas para dirigir el aprendizaje dentro del aula.

\section{A modo de conclusión}

En el Sur de Yucatán las condiciones socioeconómicas, la migración y el alto rezago educativo determinan las actividades de los habitantes de Dzán, Oxkutzcab, Santa Elena y Ticul. Es en este contexto donde los jóvenes se acompañan de la tecnología de forma cotidiana y la usan para sus actividades escolares y personales.

Como se advirtió, las prácticas de uso para el beneficio propio son mucho más diversas que las del ámbito escolar, es decir aprenden a hacer manualidades, actividades como el fisoculturismo o la danza, a tener una canal de Youtube, a editar imágenes y video, pero tambien a resolver ciertas emergencias.

Para volver a los argumentos iniciales, el uso de las tecnologías está determinado en gran medida por las reglas que establece la autoridad escolar, está acotado por las instrucciones del profesor. En casa, los padres son quienes definen horarios y momentos. Fuera de estos ámbitos, los jóvenes ejercen de manera independiente las formas, lugares y situaciones para utilizar los dispositivos.

A diferencia de los padres, los jóvenes entrevistados no se vieron forzados a migrar para colaborar en la economía familiar, tampoco dejaron los estudios para ayudar en la parcela o la milpa. La mayoría cuenta con recursos suficientes para continuar sus estudios de bachillerato e incluso educación superior. La idea de migrar aparece con fines educativos o de turismo.

Es menester señalar que la presente exploración ha permitido identificar las principales prácticas de uso y las inquietudes que tienen los jóvenes yucatecos respecto a las tecnologías, en función de las necesidades e intereses de ellos y ellas, por lo que es común que los jóvenes estén realizando determinado trabajo escolar, tomándose fotos con los amigos, publicando en redes sociales y escuchando música de forma simultánea.

Finalmente, no se debe dejar de mencionar que existe una gran distancia entre aquello que se aborda en la escuela sobre la tecnología y lo que en realidad hacen los jóvenes con ella. Como señalan Pereira, Fillol y Moura (2019), las escuelas no han buscado la forma de integrar los conocimientos que adquieren los jóvenes de forma inde- 
pendiente. Ahora bien, para los docentes, las tecnologías sí representan oportunidades de aprendizaje pese que a los alumnos no les interesa lo que ven en la clase sobre el tema. En cuanto al teléfono celular, los maestros lo perciben más como un gran distractor que como una herramienta para el aprovechamiento de los jóvenes.

Afirmamos por ahora que los programas de estudio, las materias de tecnología e informática en la zona Sur del estado de Yucatán deberían estar acompañando las prácticas de uso mencionadas y los intereses de los propios jóvenes para que la institución escolar los alcance en su transcurrir por el espacio tecnológico y virtual.

\section{Referencias}

Alvarado, L. y Pinilla, E. (2017). Usos y apropiación social de las Tecnologías de Información y Comunicación TIC en las emisoras comunitarias colombianas La Cometa de San Gil y La Esquina Radio de Medellin (Tesis Doctoral). Colombia: Universidad Pontificia Bolivariana.

Basto, A. (2015). Director de Indemaya. Recuperado el 19 de febrero de 2019, de https://www.youtube.com/watch?v=PZYXO3-yNw8

Cardón, D. (2005). La innovación por el uso. En Ambrosi, M., Peugeot, V. y Pimienta, D. (Coord.) Palabras en Juego: enfoques multiculturales sobre las sociedades de la información. Francia: C\&F éditions.

Casanova, S. (2016), Desde 'el otro lado' en Juventud rural y migración mayahablante. Acechar, observar e indagar sobre una temática emergente. En Cornejo, Inés (coordinadora). Universidad Autónoma Metropolitana, Unidad Cuajimalpa.

Cornejo, I. (2016), Joven mayahablante migrante en Juventud rural y migración mayahablante. Acechar, observar e indagar sobre una temática emergente. En Cornejo (coordinadora). Universidad Autónoma Metropolitana, Unidad Cuajimalpa.

Consejo Estatal de Población (COESPO). (2010). Índices de intensidad Migratoria México-Estados Unidos 2010. México: COESPO Yucatán. Recuperado el 2 de junio de 2017, de http://coespo.yucatan.gob.mx/general/Migracion_Yucatan_EUA. pdf

Consejo Nacional de Evaluación de la Política de Desarrollo Social (CONEVAL). (2015). Informe anual sobre la Situación de Pobreza y Rezago Social 2015: Dzán. México: CONEVAL. Recuperado el 7 de septiembre de 2016, de http://www.gob. $\mathrm{mx} / \mathrm{cms} /$ uploads/attachment/file/47264/Yucatan_025.pdf

(2015). Informe anual sobre la Situación de Pobreza y Rezago Social 2015: Oxkutzcab. México: CONEVAL. Recuperado el 7 de septiembre de 2016, de http:/www.gob.mx/cms/uploads/attachment/file/47295/Yucatan_056.pdf 
(2015). Informe anual sobre la Situación de Pobreza y Rezago Social 2015: Santa Elena. México: CONEVAL. Recuperado el 7 de septiembre de 2016, de http:// www.gob.mx/cms/uploads/attachment/file/47305/Yucatan_066.pdf_

------- (2015). Informe anual sobre la Situación de Pobreza y Rezago Social 2015: Ticul. México: CONEVAL. Recuperado el 7 de septiembre de 2016, de http://www.gob. $\mathrm{mx} / \mathrm{cms} /$ uploads/attachment/file/47328/Yucatan_089.pdf

(2014). Informe anual sobre la Situación de Pobreza y Rezago Social 2014: Ticul. México: CONEVAL. Recuperado de http://www.gob.mx/cms/uploads/ attachment/file/47222/Yucatan_089.pdf

- (2012). Informe de Pobreza y evaluación en el estado de Yucatán 2012. México: CONEVAL. Recuperado el 2 de junio de 2017, de http://www.coneval.org.mx/ coordinacion/entidades/Documents/Informes $\% 20 \mathrm{de} \% 20$ pobreza $\% 20 \mathrm{y} \% 20$ evaluaci $\%$ C3\%B3n\%202010-2012_Documentos/Informe\%20de\%20pobreza\%20y\%20evaluaci\%C3\%B3n\%202012_Yucat\%C3\%A1n.pdf

Contreras, A. (2017). La Bula de la Santa Cruzada en Nueva España: implantación y consecuencias. Antrópica. Revista de Ciencias Sociales y Humanidades. Año 3, Vol. 1, núm. 5, 181-189. Recuperado el 26 de noviembre de 2018, de http:/www.antropologia.uady.mx/revista/antropica/num05/5_1_Pon_Contreras.pdf

De Certeau, M. (2000). La invención de lo cotidiano I. Artes de hacer (1 ${ }^{a}$. reimpresión de la primera edición en español). México: Universidad Iberoamericana, Instituto Tecnológico de Estudios Superiores de Occidente.

Diario Oficial de la Federación (30 de noviembre de 2016). DECRETO por el que se formula la Declaratoria de las Zonas de Atención Prioritaria para el año 2017. Recuperado el 19 de febrero de 2019, de http://www.dof.gob.mx/nota_detalle.php ?codigo $=5463189 \&$ fecha $=30 \% 2 \mathrm{~F} 11 \% 2 \mathrm{~F} 2016$

Estrella, W. (2014). El papel de la migración internacional en los procesos de comunicación interpersonal de los jóvenes no-migrantes (Tesis de Licenciatura). México: Universidad Autónoma de Yucatán

Fernández, R. (2002). Nuevas tecnologías, educación y sociedad. En Sevillano, M. (coord.) Nuevas tecnologías, medios de comunicación y educación: formación inicial y permanente del profesorado. España: Editorial CCS.

Fornasari, M. (2014) Los jóvenes de contextos rurales y su relación con las TIC en San Luis, Argentina. Chasqui, no. 125. https://ri.conicet.gov.ar/handle/11336/6996

Fundación BBVA Bancomer A.C., Consejo Nacional de Población. (2017). Anuario de Migración y Remesas 2017. México: Fundación BBVA Bancomer, CONAPO. Recuperado el 7 de noviembre de 2017, de https:/www.gob.mx/conapo/ documentos/anuario-de-migracion-y-remesas-mexico-2017 
Anuario de Migración y Remesas 2017. Fichas por entidad federativa. 31 Yucatán. México: Fundación BBVA Bancomer, CONAPO. Recuperado el 7 de noviembre de 2017, de http://migracionyremesas.org/tb/?a=135731

Greenhow, C. \& Lewin, C. (2016) Social media and education: reconceptualizing the boundaries of formal and informal learning. Learning, Media and Technology, 41(1), 6-30, https://doi.org/10.1080/17439884.2015.1064954

Grimson, A. (2001). Interculturalidad y comunicación. Colombia: Grupo Editorial Norma.

Instituto Nacional de Estadística y Geografía (INEGI). (2017). Anuario estadistico y geográfico de Yucatán 2017. México: INEGI. Recuperado el 22 de enero de 2018, de https://www.datatur.sectur.gob.mx/ITxEF_Docs/YUC_ANUARIO_PDF.pdf (2015). Encuesta Intercensal 2015. México: INEGI. Recuperado el 13 de junio de 2017, de http://www.beta. inegi.org. $\mathrm{mx} /$ proyectos/enchogares/especiales/intercensal/?init=1

Instituto Tecnológico Superior del Sur del Estado de Yuctán (consultado el 8 de marzo de 2017). Zona de influencia. Disponible en http://itsyucatan.edu.mx/nuestro-tec/ zona-de-influencia/

Itchart, L. y Donati, J. (2014). Prácticas Culturales. Argentina: Universidad Nacional Arturo Jauretche.

May May, Ismael. 2010. El maya escrito a través de los medios electrónicos de comunicación: localizando lo global. En Etnia, lengua y territorio. El sureste ante la globalización. Ricardo López Santillán, coord., México: CPHS, UNAM.

Murcia, N., Jaimes, S \& Gómez, J. (2016). La práctica social como expresión de humanidad. Cinta de moebio, (57), 257-274. https://dx.doi.org/10.4067/ S0717-554X2016000300002

Olvera, R. (2016). Jóvenes y migración en Mamita, Yucatán. En Cornejo, I. (coord.) Juventud rural y migración mayahablante. Acechar, observar e indagar sobre una temática emergente. México Universidad Autónoma Metropolitana Unidad Cuajimalpa. Orozco, G. (1998). Las prácticas en el contexto comunicativo. Chasqui Revista Latinoamericana de Comunicación. No. (62). Consultado el 17 de octubre de 2017 en https://dialnet.unirioja.es/servlet/articulo?codigo $=5791542$

Pereira, S., Fillol, J. \& Moura, P. (2019). El aprendizaje de los jóvenes con medios digitales fuera de la escuela: De lo informal a lo formal. Revista Comunicar, no 58, v. XXVII, 41-50.

Secretaría de Desarrollo Social (SEDESOL) (2017). Informe anual sobre la Situación de Pobreza y Rezago Social 2017: Dzán. México: SEDESOL. Recuperado el 7 de mayo de 2017, de http://diariooficial.gob.mx/SEDESOL/2017/Yucatan_025.pdf 
(2017). Informe anual sobre la Situación de Pobreza y Rezago Social 2017: Oxkutzcab. México: SEDESOL. Recuperado el 7 de mayo de 2017, de http:// diariooficial.gob.mx/SEDESOL/2017/Yucatan_056.pdf

------- (2017). Informe anual sobre la Situación de Pobreza y Rezago Social 2017: Santa Elena. México: SEDESOL. Recuperado el 7 de mayo de 2017, de http://diariooficial.gob.mx/SEDESOL/2017/Yucatan_066.pdf

-------- (2017). Informe anual sobre la Situación de Pobreza y Rezago Social 2017: Ticul. México: SEDESOL. Recuperado el 7 de mayo de 2017, de http://diariooficial.gob. $\mathrm{mx} /$ SEDESOL/2017/Yucatan_089.pdf

Secretaría de Educación de Yucatán (SEGEY). (2016). Estadísticas ciclo escolar 20152016. Recuperado el 27 de mayo de 2017, de http://www.educacion.yucatan.gob. mx/estadistica/estadistica

Secretaría de Gobernación (SEGOB). (2017). Boletín mensual de estadísticas migratorias 2017. México: SEGOB. Recuperado el 21 de enero de 2019, de http://www.politicamigratoria.gob.mx/work/models/SEGOB/CEM/PDF/Estadisticas/Boletines_ Estadisticos/2017/Boletin_2017.pdf

(2016). Boletín mensual de estadisticas migratorias 2016. México: SEGOB. Recuperado el 21 de noviembre de 2017, de http://www.politicamigratoria.gob.mx/work/models/SEGOB/CEM/PDF/ Estadisticas/Boletines_Estadisticos/2016/Boletin_2016.pdf

(2015). Boletín mensual de estadisticas migratorias 2015. México: SEGOB. Recuperado el 21 de noviembre de 2017, de http:/www.politicamigratoria.gob.mx/work/models/SEGOB/CEM/PDF/ Estadisticas/Boletines_Estadisticos/2015/Boletin_2015.pdf

(2014). Boletín mensual de estadísticas migratorias 2014. México: SEGOB. Recuperado el 21 de noviembre de 2017, de http://www.politicamigratoria.gob.mx/work/models/SEGOB/CEM/PDF/ Estadisticas/Boletines_Estadisticos/2014/Boletin_2014.pdf

(2013). Boletín mensual de estadisticas migratorias 2013. México: SEGOB. Recuperado el 21 de noviembre de 2017, de http://www.politicamigratoria.gob.mx/work/models/SEGOB/CEM/PDF/ Estadisticas/Boletines_Estadisticos/2013/Boletin_2013.pdf

(2012). Boletín mensual de estadisticas migratorias 2012. México: SEGOB. Recuperado el 21 de noviembre de 2017, de http://www.politicamigratoria.gob.mx/work/models/SEGOB/CEM/PDF/ Estadisticas/Boletines_Estadisticos/2012/Boletin2012.pdf

(2011). Boletín mensual de estadisticas migratorias 2011. México: SEGOB. Recuperado el 21 de noviembre de 2017, 
de http:/www.politicamigratoria.gob.mx/work/models/SEGOB/CEM/PDF/ Estadisticas/Boletines_Estadisticos/2011/BoletinEst2011.pdf

(2010). Boletín mensual de estadisticas migratorias 2010. México: SEGOB. Recuperado el 21 de noviembre de 2017, de http://www.politicamigratoria.gob.mx/work/models/SEGOB/CEM/PDF/ Estadisticas/Boletines_Estadisticos/2010/BoletinEst2010.pdf

Silva, M. (2008). Educación interactiva. Enseñanza y aprendizaje presencial y on-line. Editorial Gedisa. España.

Uribe Fernández, M. (2014). La vida cotidiana como espacio de construcción social. Procesos Históricos, (25), 100-113. Consultado el 20 de mayo de 2019 en https://www.redalyc.org/html/200/20030149005/

Valencia, J. y Magallanes, C. (2015). Prácticas Comunicativas y cambio social: potentia, acción y reacción. Universitas Humanistica, no.81 enero-junio de 2015 pp: 15-31. Consultado el 27 de noviembre de 2017 en https://revistas.javeriana.edu.co/index. php/univhumanistica/article/view/14885/12020 